\title{
Perception of Risk, Severity of Disease and Preventive Behaviors of COVID-19 in a New Epidemic Situation among People in Samut Songkhram Province, Thailand
}

\author{
Wongpituk, K., ${ }^{1 *}$ Tanthanapanyakorn, P., ${ }^{1}$ Sanguanchue, A., ${ }^{1}$ Saykaew, T. ${ }^{1}$ and Chankong, W. ${ }^{2}$ \\ ${ }^{1}$ Faculty of public health, Valaya Alongkorn Rajabhat University under the Royal Patronage Pathum-Thani, \\ Thailand, E-mail: klarnarong.wong@vru.ac.th \\ ${ }^{2}$ School of Health Sciences, Sukhothai Thammathirat Open University, Thailand \\ ${ }^{*}$ Corresponding Author
}

DOI: https://doi.org/10.52939/ijg.v17i5.2017

\begin{abstract}
The interesting scenario involving COVID-19's breakout in multiple nations is still serious in many areas of the world. This perceived risk can significantly increase compliance with COVID-19 prevention behaviors during the next pandemic. The purpose of this study was to explore how people perceive COVID-19 risk, disease severity, and COVID-19 prevention in Samut Songkhram province, Thailand. A study examined the relationship between people's perceptions of risk, COVID-19 severity, and COVID-19 prevention activity. The COVID-19 issue was the subject of this cross-sectional investigation, using a Geographic Information System. A cross-sectional study on perception of COVID-19 risk, disease severity, and COVID-19 prevention. Explore the relationship between the people's perception of COVID-19 risk, disease severity, and COVID-19 prevention behaviors. Descriptive statistics, such as frequency distribution methods, mean, standard deviation. Analytical statistics, such as correlation and multiple regression, were used to analyze the data. This study found that the female to male ratio is around 1:2. The age group with the most representation was 15-26 years old. The results showed that people's perception of COVID-19 risk had no relationship to COVID-19 preventive behaviors. People's perception of COVID-19 severity was shown to be significantly associated with COVID-19 prevention behaviors at 0.001. The multiple regression equation to estimate COVID-19 prevention behaviors in a new epidemic; $P$ (the COVID-19 prevention) $=4.344-0.115$ Female $\left(X_{1}\right)+0.141$ Farmer $\left(X_{2}\right)+0.356$ Trading $\left(X_{3}\right)+0.733$ Traveled to an endemic area $\left(X_{4}\right)+0.253$ Age, 28-36 years $\left(X_{5}\right)$ - 0.546 Age, 37-46 years $\left(X_{6}\right)+0.317$ Age, 47-56 years $\left(X_{7}\right)+0.151$ Age, $>56$ years $\left(X_{8}\right)+$ 0.318 The perception of COVID-19 severity $\left(X_{9}\right)-0.092$ The perceptions of COVID-19 risk $\left(X_{10}\right)$. The results of this study will be used to establish an intervention model for encouraging and establishing effective COVID-19 preventive practices, as well as maintaining and continuing them.
\end{abstract}

\section{Introduction}

In many parts of the world, the intriguing scenario surrounding COVID-19's breakout in several countries is still serious on July 11, 2021. Rajasthan, India, declared that the weekend curfew has been lifted and COVID-19 control measures are relaxed as the number of instances has decreased. Multiplexes and theaters are permitted to operate at $50 \%$ capacity, from 9 am until $8 \mathrm{pm}$. People who have received at least one dose of the COVID-19 vaccination can now access skills development facilities. Due to the growing COVID-19 crisis, the Republic of Singapore has made it illegal for people from other nations to enter the country unless they are a permanent resident of Singapore. This ban will take effect from July 10, 2021. Furthermore, from July 12, 2021, any tourists who have traveled to
Indonesia within 21 days of transiting italics Singapore will be denied entry. Masks are nevertheless required to be worn in several public locations, including public transportation, congested spaces, poorly ventilated interior areas, and keeping social distance, according to the Welsh government. When the final action plan to terminate COVID-19 is a must, lockdown measures is finished on July 19, 2021, the legal necessity to wear a mask will be lifted. In collaboration with the COVID-19 Task Force and U-INSPIRE, UNESCO Office Jakarta developed a risk communication for society awareness of COVID-19 with the help of WHO and UNIC. The article focuses on three categories of COVID-19 patients: those who have no symptoms, those who are being watched, and those who are 
being treated. The COVID-19 Task Force message included, among other things, risk communication messages. \# do not return to the villages, \# remain at home, \# physical distancing, \# always wear a mask, and \# wash your hands with soap and water (UNESCO, 2020).

Thailand's efforts, according to the Center for Covid-19 Situation Administration, include the creation of zones to improve COVID-19 control. The immediate implementation of integrated control measures in certain regions, such as Bangkok and its environs. Limit people's travel for at least two weeks, both from home and across provinces. Asking for their assistance in refraining from needless travel, save for the provision of consumer items, visiting a hospital vaccination, or the necessity of going to work, as of July 12, 2021. The coronavirus (COVID-19) is presently infecting 85,689 people in Thailand, who are being treated in hospitals, field hospitals, and hospitel. There were 2,783 serious cases, up from 584 the previous week, with 728 requiring intubation (125 increase) Bangkok dealt with 298 intubated patients (40.9\%), Samut Prakan with 53 patients $(7.2 \%)$, Nonthaburi with 44 patients $(6.0 \%)$, and Nakhon Pathom with 40 patients (The Centre for the Administration of the Situation due to the Outbreak of the Communicable Disease Coronavirus 2019 (COVID19, 2021). There was a system in place to closely evaluate symptoms on a daily basis and to set up a referral system for patients who needed to be the hospitalized. Patients are categorized based on the severity of their symptoms, and those with mild symptoms should be treated in specialized hospitals or in home isolation. Thailand is experiencing a fresh wave of the Covid-19 epidemic. The latest wave of Covid-19 spread in Thailand was another cluster occurrence, however this time it was dispersed over many places. Covid-19 was distributed to a significant number of provinces as a result of this incident. The source may be tracked down to a wholesale shrimp market in Samut Sakhon Province in mid-December 2020. The majority of the first infections occurred among Thai residents and non-Thai migrants living and working in the area. The crowded living circumstances of the migrants in the neighboring neighborhood, as well as a lack of personal care to avoid transmission, were factors for the epidemic. Walk-in patients with symptoms, contact tracing, and community outreach screening were used to identify instances of Covid19. All factories in the province were under sample monitoring. Many traders from all across Thailand come to the shrimp market on a daily basis to acquire goods to sell in their home province's fresh markets. As a result, the first cluster of illnesses had the potential to spread extensively, resulting in smaller clusters of infections in several provinces in the weeks that followed. As a result of this incident, the government decided to re-impose containment measures in Samut Sakhon Province, but in a more targeted manner. For example, 1) the wholesale shrimp market in Samut Sakhon was closed, 2) the Sri Muang apartment building adjacent to the shrimp market in Samut Sakhon was locked down, 3) other businesses' hours of operation were limited, 4) movement in apartment buildings was restricted at certain times of the day/night, and 5) non-Thai migrants were prohibited from traveling outside the area (Disease Control, Ministry of Public Health, Thailand, 2021).

The COVID-19 preventative behaviors were linked to the perceived risk factor. During the new pandemic, this perceived risk can significantly increase involvement in COVID-19 preventative behaviors (Yildirim et al., 2021). The people groups' perceptions of COVID-19 severity as well as preventive measures for COVID-19 were high (Quandt et al., 2020). The goal of this study was to examine people's perceptions of COVID-19 risk, disease severity, and COVID-19 preventive behavior as well as to examine the relationships between people's perception of risk, perceived severity of COVID-19, with COVID-19 preventative behavior in Samut Songkhram province, Thailand.

\section{Method}

\subsection{Research Objective}

The study's goal was to explore people's perceptions of COVID-19 risk, disease severity, and COVID-19 prevention behaviors. In addition, the study wanted to explore a relationship between risk perception, COVID-19 severity, and COVID-19 prevention behaviors.

\subsection{Research Design}

This study was a cross-sectional research into the COVID-19 crisis. Samut Songkhram province was chosen as the study location, shown by Figure 1. The study period included from June 2020 to February 2021. As included 163,862 people in Samut Songkhram province who were 15 years old or older, could read and write, and volunteered to take part in the study. The sample size was calculated using the Taro Yamane formula (Yamane, 1973), and the stratified sampling procedure gave a sample size of 400 people. A questionnaire was used as the research document. Part 1, included sex, age, marital status, educational level, occupation, income, social position, and a family member's history of COVID-19. 


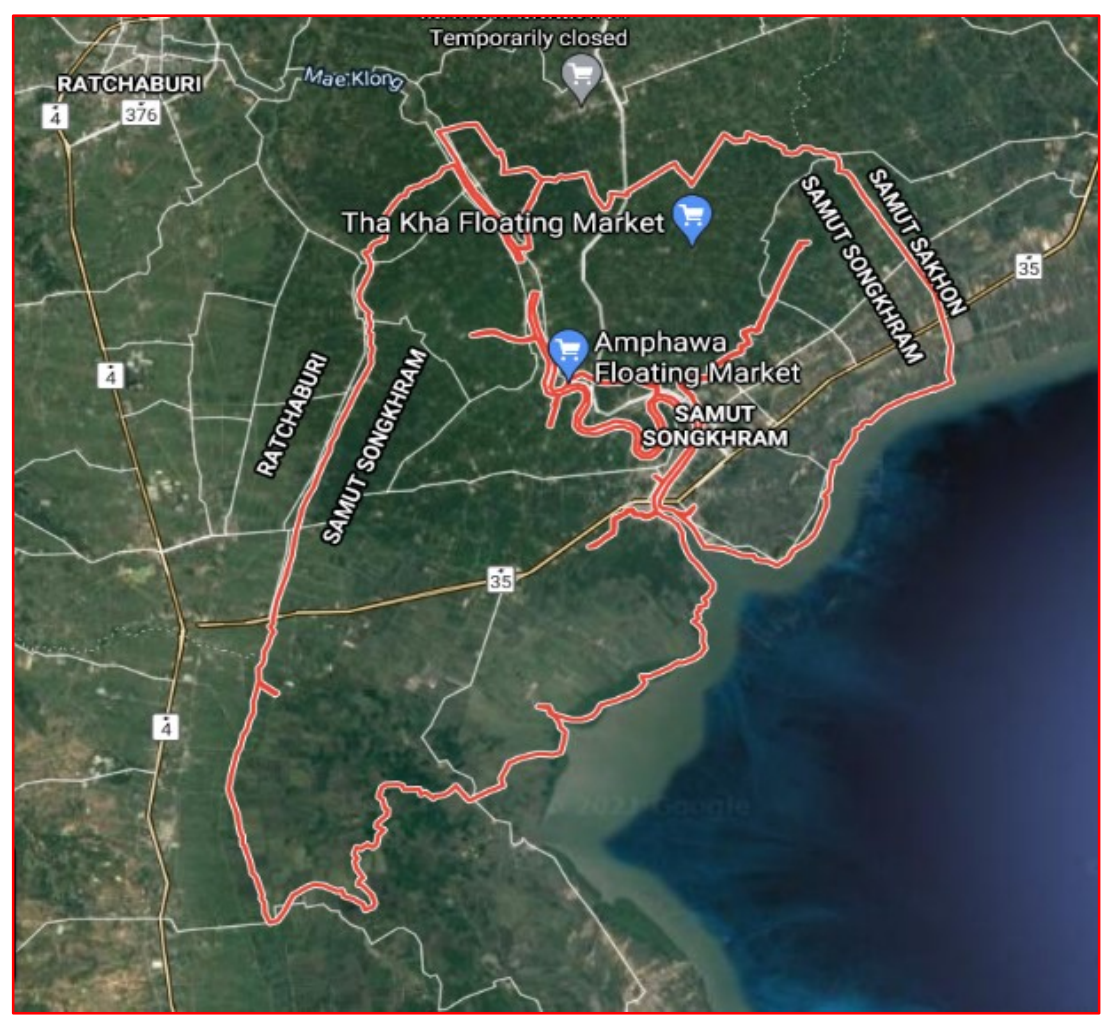

Figure 1: Map of Samut Songkhram province

Part 2, the perceived risk exposure for COVID-19 consists of positive and negative questions with a 5point rating scale for answers. Part 3, the COVID-19 preventive behaviors are divided into positive and negative questions, with a 5-point rating scale as the answer. Five experts evaluated the content validity of the document to determine its quality. The confidence was assessed using the alpha coefficient technique (Cronbach, 1970), and the questionnaire level was taken to improve according to expert recommendations and to gather real data. This study collected data on sex, age, marital status, educational level, occupation, income, social position, and a family member's history of COVID19 , as well as the perceived risk factors and severity of COVID-19. COVID-19 prevention behaviors were connected to personal characteristics, perceived risk factors, and perceived severity of COVID-19 factors. Used GIS to generate spatial mapping for timely and effective spatial solution planning. The data was examined using descriptive statistics including frequency distribution methods, mean, standard deviation, and the Chi-Square Test to assess the correlation.

\section{Result}

According to the findings of this study, the female to male ratio is around 1:2. The age group with the most representation was $15-26$ years old $(68.5 \%)$. The greatest percentage of singles was 79.80 , the highest percentage of education was 29.00 with a bachelor's degree or more, the highest percentage of occupation was 37.80 with others, and the highest percentage of family members at risk was 89.00 with none, as shown in Table 1.

Using correlation statistical analysis to identify the relationship from Table 2. The people's perception of COVID-19 risk had no relationship to COVID-19 preventive behaviors. At the level of 0.001, the perception of infection with COVID-19 was significantly related to COVID-19 prevention behaviors, and the relation was in the same direction $(r=0.22)$, low level relationship. Hand washing with soap is another way to reduce the danger of spreading COVID-19. There was a significant relationship between COVID-19 prevention behaviors and hand washing with soap, at the level of 0.001, and in the same direction as the relationship ( $\mathrm{r}=0.30)$, moderate level relationship. Fever, cough, and sneezing rapidly replaced medical care for diagnosis and treatment. 
Table 1: Personal factor of respondents in Samut Songkhram province, 2021

\begin{tabular}{|l|c|c|}
\hline \multicolumn{1}{|c|}{ Personal factor } & number(400) & $\begin{array}{c}\text { Proportion(\%) of each } \\
\text { category }\end{array}$ \\
\hline Sex & & 62.00 \\
\hline Male & 248 & 38.00 \\
\hline Female & 152 & 68.50 \\
\hline Age & 274 & 4.50 \\
\hline $15-26$ years & 18 & 4.50 \\
\hline $27-36$ years & 18 & 4.50 \\
\hline $37-46$ years & 18 & 18.00 \\
\hline $47-56$ years & 72 & \\
\hline$>56$ years & & 79.8 \\
\hline Marital status & 319 & 18.00 \\
\hline Single & 72 & 2.30 \\
\hline Marry & 9 & 18.00 \\
\hline Widow & & 13.50 \\
\hline Education & 72 & 13.00 \\
\hline Elementary school, & 54 & 26.50 \\
\hline Junior high school & 52 & 29.00 \\
\hline High school & 106 & \\
\hline Diploma, & 116 & 19.80 \\
\hline Bachelor's degree or higher & & 13.50 \\
\hline Occupation & 79 & 11.30 \\
\hline Farmer & 54 & 17.80 \\
\hline Trade & 45 & 37.80 \\
\hline Laborer & 71 & 89.00 \\
\hline Housewife & 151 & 4.30 \\
\hline Others & 356 & 6.80 \\
\hline Family members at risk & 17 & \\
\hline None & 27 & \\
\hline Traveled to an endemic area & & \\
\hline Traveled to a crowded areas & & \\
\hline
\end{tabular}

Table 2: The relationship between the perceptions of COVID-19 risk and COVID-19 prevention behaviors

\begin{tabular}{|l|c|c|c|}
\hline \multicolumn{1}{|c|}{ Factors } & $\begin{array}{c}\text { Pearson } \\
\text { Correlation(r) }\end{array}$ & $\begin{array}{c}\text { Sig. } \\
\text { (2-tailed) }\end{array}$ & Relationship level \\
\hline The perceptions of COVID-19 risk & 0.08 & 0.096 & Non relationship \\
\hline Perception of infection with COVID-19 & 0.22 & $0.001^{* *}$ & $\begin{array}{c}\text { Low level } \\
\text { relationship }\end{array}$ \\
\hline $\begin{array}{l}\text { The organization of crowded events increases } \\
\text { the risk of spreading covid-19. }\end{array}$ & -0.18 & $0.001^{* *}$ & $\begin{array}{c}\text { Inverse low level } \\
\text { relationship }\end{array}$ \\
\hline $\begin{array}{l}\text { Hand washing with soap is another way to } \\
\text { reduce the risk of spreading COVID-19. }\end{array}$ & 0.30 & $0.001^{* *}$ & $\begin{array}{c}\text { Moderate level } \\
\text { relationship }\end{array}$ \\
\hline $\begin{array}{l}\text { Coming/walking in the opposite direction } \\
\text { increases the risk of contracting covid-19. }\end{array}$ & -0.18 & $0.001^{* *}$ & $\begin{array}{c}\text { Inverse low level } \\
\text { relationship }\end{array}$ \\
\hline $\begin{array}{l}\text { Fever, cough, and sneezing require immediate } \\
\text { medical attention for examination and } \\
\text { treatment. }\end{array}$ & 0.31 & $0.001^{* *}$ & $\begin{array}{c}\text { Moderate level } \\
\text { relationship }\end{array}$ \\
\hline $\begin{array}{l}\text { The fortinet stay home campaign can reduce } \\
\text { the risk. }\end{array}$ & 0.03 & 0.593 & Non relationship \\
\hline
\end{tabular}

$* * p<0.01$ 


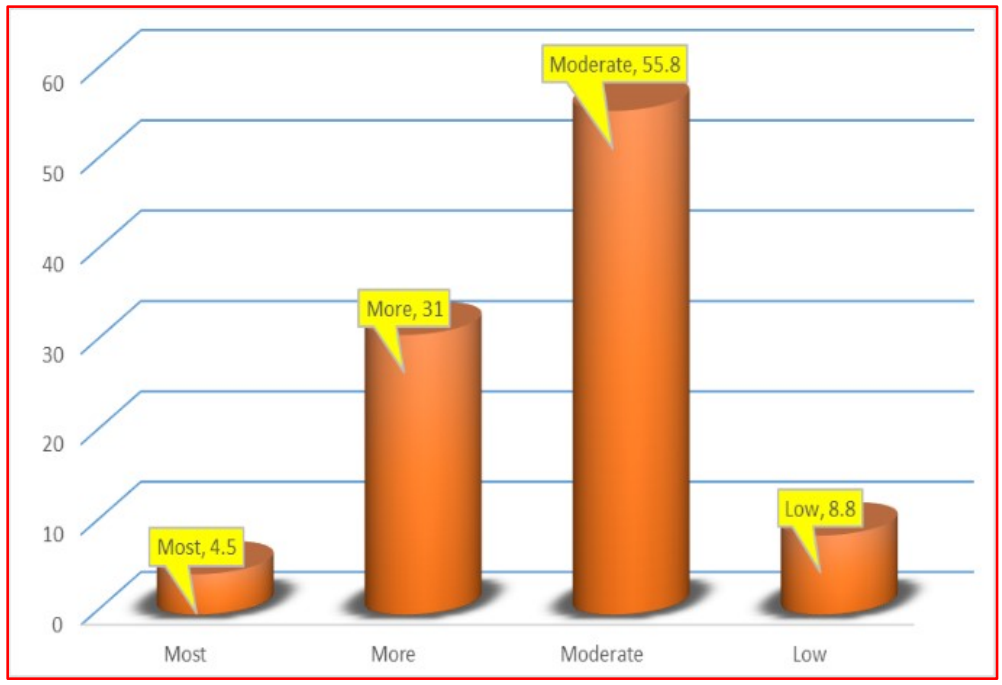

Figure 2: The perceptions of COVID-19 risk

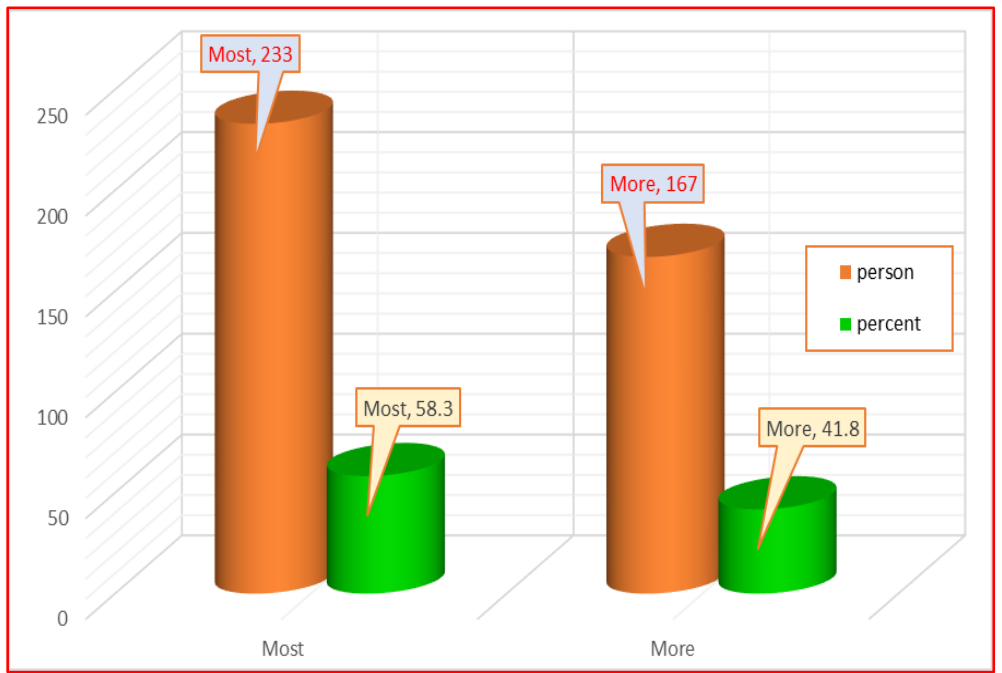

Figure 3: The level of the perception of COVID-19 severity

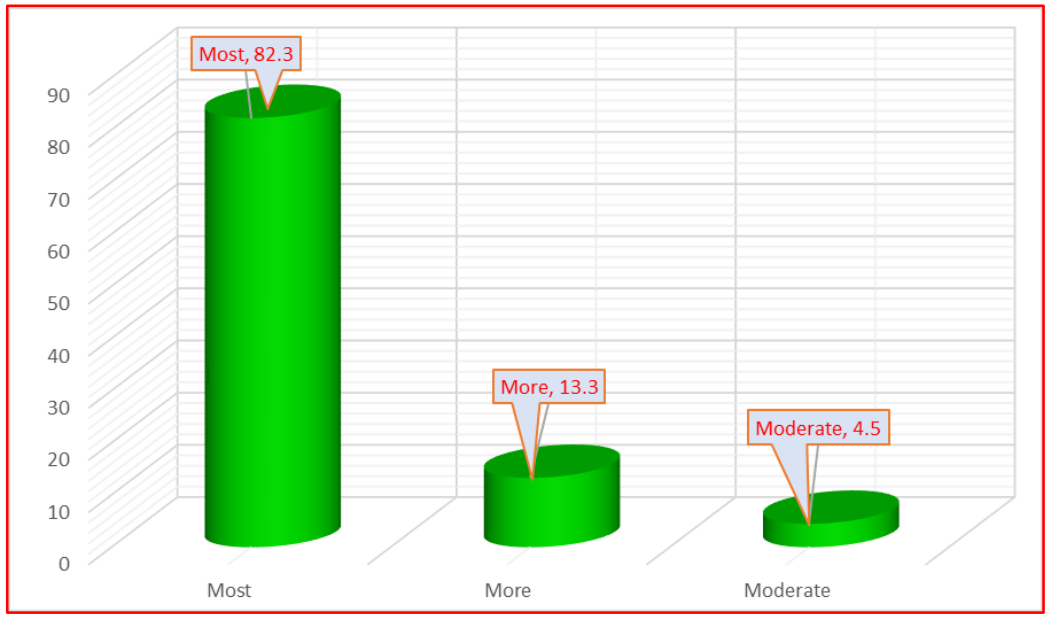

Figure 4: The level of the COVID-19 prevention behaviors 
Fever, cough, and sneezing have a strong association with COVID-19 prevention behaviors, at a level of 0.001 , and in the same direction $(\mathrm{r}=0.31)$, moderate level relationship. While organizing crowded events increases the danger of spreading COVID-19 and coming/walking in the other direction increases the chance of contracting COVID-19, there was a significant relationship with COVID-19 prevention behaviors at the level of 0.001 in the inverse direction $(\mathrm{r}=-0.18)$, low level relationship. However, the fortinet stay home campaign can reduce the risk and has nothing to do with COVID-19 prevention behaviors. Figure 2 shows that the majority of respondents (55.8\%) indicated the perceptions of COVID-19 risk was moderate, followed by more level, low level, and most level, with $31.00 \%, 8.8 \%$, and $4.5 \%$, respectively. While the findings overall showed that Muang Samut Songkhram district had the highest level of perceptions of COVID-19 risk, Bang Khonthi district had the high level of perceptions of COVID-19 risk, and Amphawa district had a moderate level of perceptions of COVID-19 risk, represent in Figure 5.

The relationship was discovered using correlation statistical analysis. People's perception of COVID-19 severity was shown to be significantly associated with COVID-19 prevention behaviors at 0.001 , and in the same direction $(\mathrm{r}=0.26)$, low level relationship. COVID-19 severity increases with age was shown to be significantly associated with COVID-19 prevention behaviors at a 0.001 level, and in the same direction $(\mathrm{r}=0.38)$, moderate level relationship. There was a significant relationship between COVID-19 prevention behaviors and patients with heart problems were more likely to die if they are infected with COVID-19, at the level of 0.05 , and in the same direction as the relationship $(r=0.12)$, a low level relationship. Acute airway infection and pneumonia were the major causes of death associated with COVID-19 prevention behaviors, with a 0.001 level of association and a moderate level connection $(r=0.41)$ in the same direction. Furthermore, the severity of this condition varies from one person to the next, and there was a significant association with COVID-19 prevention behaviors at the level of 0.001 in the same direction $(\mathrm{r}=-0.25)$, at a low level, as shown in Table 3. Figure 3 reveals that the majority of respondents, $82.30 \%$ indicated that perceptions of COVID-19 severity were at the highest level, followed by 167 people $(41.8 \%)$, at the more level. COVID-19 preventive behaviors were ranked highest by $82.30 \%$ of respondents, followed by $13.30 \%$ at a high level, and $4.50 \%$ at a moderate level, as shown in Figure 4. The overall showed that Muang Samut Songkhram district and Amphawa district had the highest perceptions of COVID-19 severity, and Bang Khonthi district had the high level of perceptions of COVID-19 severity, represent by Figure 6. However, the results overall showed that Muang Samut Songkhram district and Amphawa district had the highest level of COVID19 preventive behaviors, and Bang Khonthi district had the high level of COVID-19 preventive behaviors, represented in Figure 7.

The study demonstrated the use of a multiple regression equation of variables to estimate COVID19 prevention behaviors in a new epidemic scenario among people in Thailand's Samut Songkhram area. The results revealed that the $\mathrm{P}$ equation, $\mathrm{P}$ (the COVID-19 prevention) $=4.344-0.115$ Female $\left(X_{I}\right)$ +0.141 Farmer $\left(X_{2}\right)+0.356$ Trading $\left(X_{3}\right)+0.733$ Traveled to an endemic area $\left(X_{4}\right)+0.253$ Age, 28-36 years $\left(X_{5}\right)-0.546$ Age, 37-46 years $\left(X_{6}\right)+0.317$ Age, $47-56$ years $\left(X_{7}\right)+0.151$ Age, $>56$ years $\left(X_{8}\right)+0.318$ The perception of COVID-19 severity $\left(X_{9}\right)-0.092$ The perceptions of COVID-19 risk $\left(X_{10}\right)$, as shown in Table 4.

Table 3 The relationship between the perceptions of COVID-19 severity and COVID-19 prevention behaviors

\begin{tabular}{|l|c|c|c|}
\hline \multicolumn{1}{|c|}{ Factors } & $\begin{array}{c}\text { Pearson } \\
\text { Correlation(r) }\end{array}$ & $\begin{array}{c}\text { Sig. } \\
\text { (2-tailed) }\end{array}$ & Relationship level \\
\hline The perceptions of COVID-19 severity & 0.26 & $0.001^{* *}$ & $\begin{array}{c}\text { Low level } \\
\text { relationship }\end{array}$ \\
\hline $\begin{array}{l}\text { COVID-19 gets more severe as you get } \\
\text { older. }\end{array}$ & 0.38 & $0.001^{* *}$ & $\begin{array}{c}\text { Moderate level } \\
\text { relationship }\end{array}$ \\
\hline $\begin{array}{l}\text { Patients with heart problems are more likely } \\
\text { to die if they are infected with COVID-19. }\end{array}$ & 0.12 & $0.013^{*}$ & $\begin{array}{c}\text { Low level } \\
\text { relationship }\end{array}$ \\
\hline $\begin{array}{l}\text { Acute airway infection and pneumonia were } \\
\text { the primary causes of mortality. }\end{array}$ & 0.41 & $0.001^{* *}$ & $\begin{array}{c}\text { Moderate level } \\
\text { relationship }\end{array}$ \\
\hline $\begin{array}{l}\text { The severity of this disease differs from one } \\
\text { individual to the next. }\end{array}$ & 0.25 & $0.001^{* *}$ & $\begin{array}{c}\text { Low level } \\
\text { relationship }\end{array}$ \\
\hline
\end{tabular}




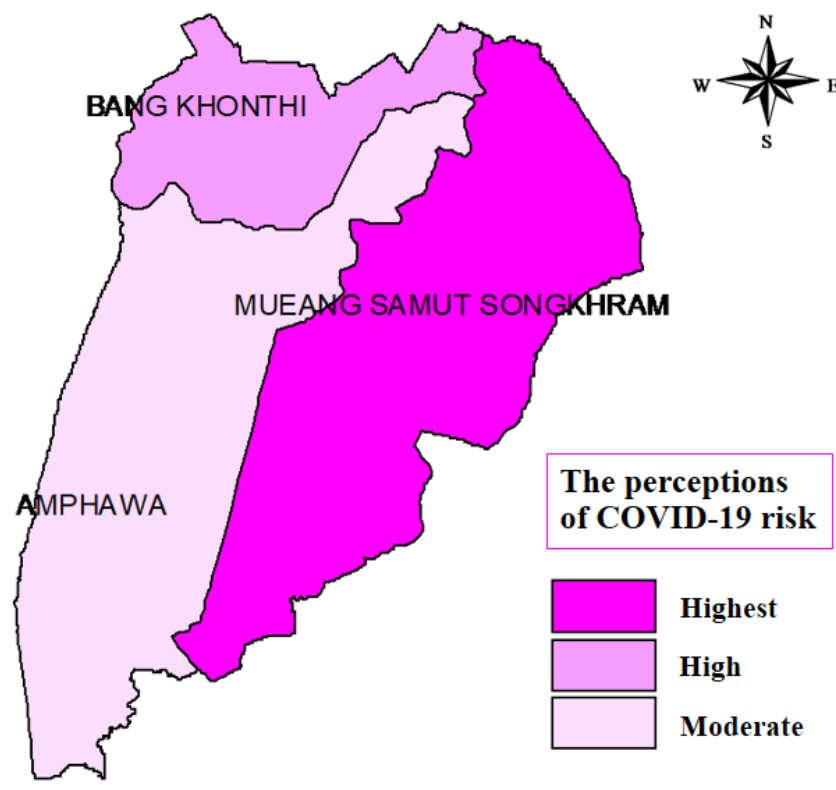

Figure 5: The perceptions of COVID-19 risk

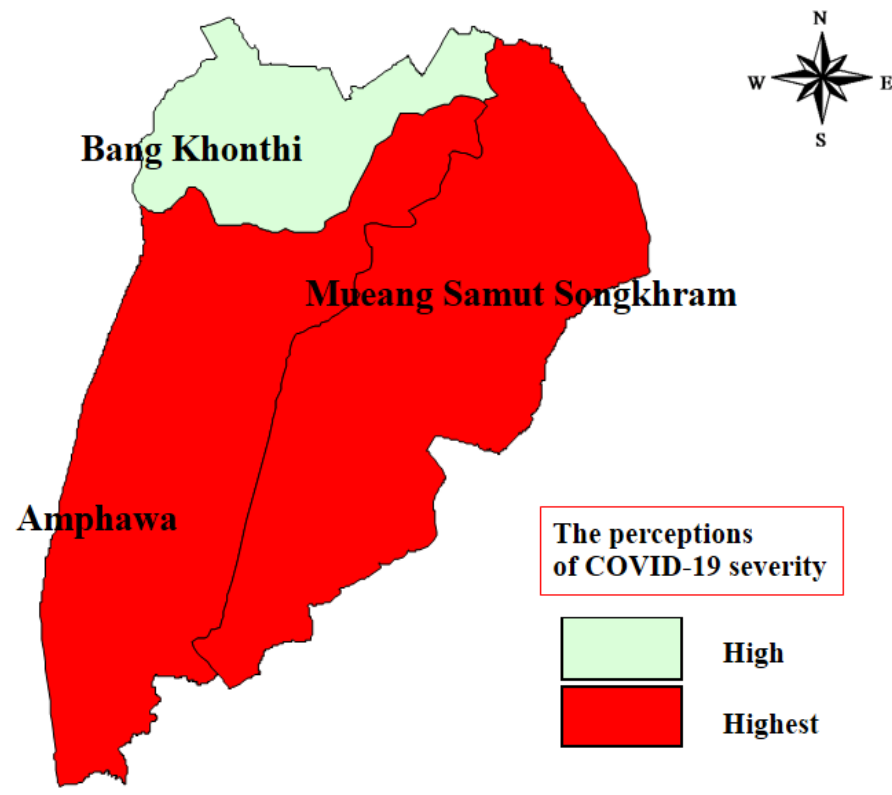

Figure 6: The perception of COVID-19 severity

Table 4: The multiple regression equation

\begin{tabular}{|l|c|c|c|c|c|}
\hline \multicolumn{1}{|c|}{ Variable } & B & S.E. & Beta & t & Sig. \\
\hline Female $\left(\mathrm{X}_{1}\right)$ & -0.115 & 0.058 & -0.129 & -1.975 & $0.049^{*}$ \\
\hline Farmer $\left(\mathrm{X}_{2}\right)$ & 0.141 & 0.059 & 0.129 & 2.394 & $0.017^{*}$ \\
\hline Trading $\left(\mathrm{X}_{3}\right)$ & 0.356 & 0.066 & 0.280 & 5.389 & $0.001^{* *}$ \\
\hline Traveled to an endemic area $\left(\mathrm{X}_{4}\right)$ & 0.733 & 0.100 & 0.339 & 7.339 & $0.001^{* *}$ \\
\hline Age, 28-36 years $\left(\mathrm{X}_{5}\right)$ & 0.253 & 0.104 & 0.121 & 2.438 & $0.015^{*}$ \\
\hline Age, 37-46 years( $\left.\mathrm{X}_{6}\right)$ & -0.546 & 0.124 & -0.260 & -4.421 & $0.001^{* *}$ \\
\hline Age, 47-56 years( $\left.\mathrm{X}_{7}\right)$ & 0.317 & 0.099 & 0.151 & 3.213 & $0.001^{* *}$ \\
\hline Age, $>56$ years $\left(\mathrm{X}_{8}\right)$ & 0.151 & 0.071 & 0.133 & 2.140 & $0.033^{*}$ \\
\hline The perception of COVID-19 severity $\left(\mathrm{X}_{9}\right)$ & 0.318 & 0.058 & 0.315 & 5.456 & $0.001^{* *}$ \\
\hline The perceptions of COVID-19 risk $\left(\mathrm{X}_{10}\right)$ & -0.092 & 0.059 & -0.090 & -1.564 & 0.119 \\
\hline Constant & 4.344 & 0.058 & & 74.440 & $0.001^{* *}$ \\
\hline
\end{tabular}




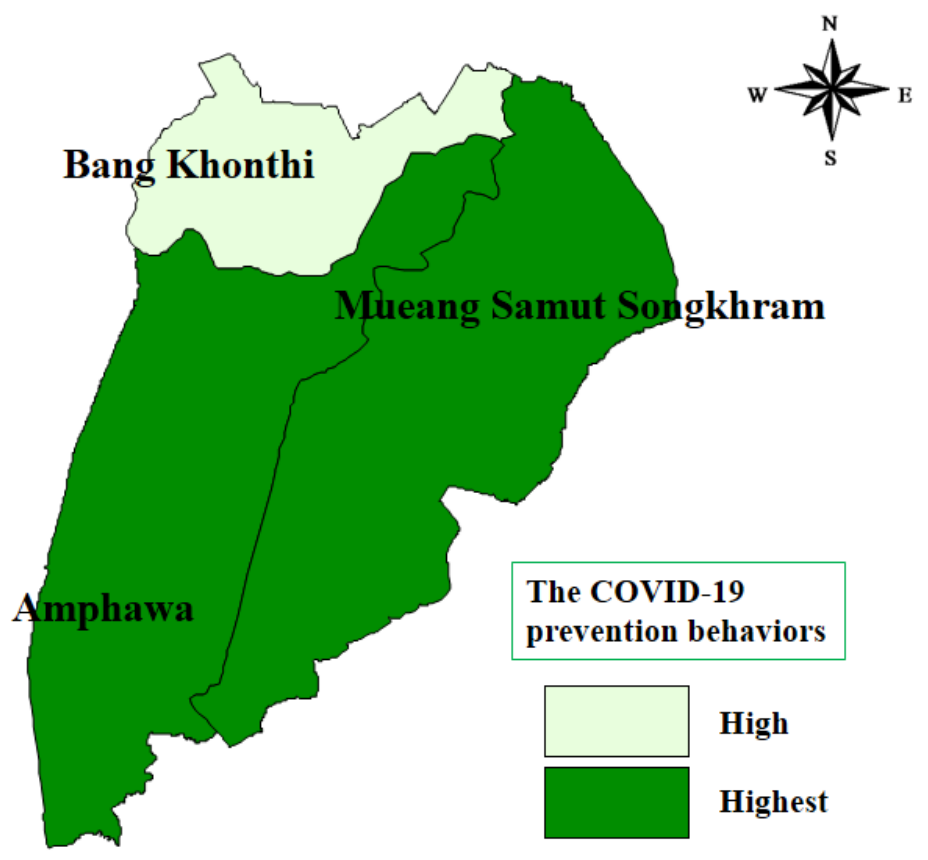

Figure 7: The COVID-19 prevention behaviors

\section{Discussion}

Overall, people's perception of COVID-19 risk is not related to the occurrence of COVID-19 epidemic preventive behaviors, according to the results. Despite the fact that the items were separated, up to five issues were discovered to have a significant relationship with the occurrence of COVID-19 epidemic preventive activities. Demonstrate the significance of developing COVID-19 risk awareness strategies or methods that are successful and suitable for that individual, community, or organization. Inconsistent with the study, "the impacts of vulnerability, perceived risk, and fear on preventive behaviors against COVID19". The findings showed that during the new COVID-19 pandemic, perceived risk might significantly increase involvement in preventative behaviors. The findings have major implications for both study and activity, of course, as pointed out by Yildirim et al., (2021). Inconsistent to the research, the community in Hong Kong has a high risk perception of COVID-19. The majority of responders were aware of COVID-19 evolution and performed protective measures for COVID-19, as pointed out by Kwok et al., (2020). Inconsistent with the findings, risk perceptions influenced intentions toward preventive behaviors, as pointed out by Sobkow et al., (2020). Inconsistant, the studies have been directed at a relationship between risk perception, prevention behaviors, and attitudes towards the COVID-19 epidemic in Bolivia. The findings revealed that risk perception is related to the adoption of preventative behaviors, as pointed out by Zeballos Rivas et al., (2021). As well as, in ten countries, risk perception was shown to be significantly related to the reported adoption of preventative health behaviors. Risk perceptions of COVID-19 around the world, as pointed out by Dryhurst et al., (2020). Inconsistent, during the COVID-19 crisis in China, risk perception was significantly related to the public's adoption of preventive action recommendations. The government intervention, risk perception, and the adoption of protective action recommendations: evidence from the COVID-19 prevention and control experience of China, as pointed out by Duan et al., (2020). Also, adherence to preventative measures among youth was highly correlated with self-perceived risk and a desire to defend others. Risk perception of COVID-19 infection and adherence to preventive measures among adolescents and young adults, as pointed out by Yang et al., (2020). Inconsistent with study, psychological and behavioral responses in South Korea during the early stages of COVID-19. The results showed precautionary behavior is closely related to perceived risk, as pointed out by Lee and You (2020). Overall, the level of perceived the severity of COVID-19 was related to COVID-19 epidemic preventive behaviors, according to the results. Despite the fact that the items were separated, up to four issues were discovered to have 
a significant relationship with the occurrence of COVID-19 epidemic preventive activities.

People perceive the severity or fatality of COVID19. People will be eager to find various ways to protect themselves against COVID-19. Self-defense behaviors such as vaccination, social distancing, as well as new normal behaviors, etc. However, the results of this research can be used as a guideline to create activities to promote the self-defense of COVID-19 people and communities. Consistent, an online cross-sectional study of Chinese residents revealed that they embraced COVID-19 protective behaviors. Increased levels of protective behaviors were shown to be associated with perceived severity, as pointed out by Ning et al., (2021). Also, adolescents' adherence to COVID-19 preventative behaviors was related with perceived severity, either directly or indirectly, as pointed out by Park and Oh (2021). Inconsistent, there was no association between perceived COVID-19 severity and some preventative measures, like avoiding public transit and restaurants, according to the findings, as pointed out by Mousavi et al., (2021). Inconsistent, the perceived severity of COVID-19 was not associated with self-reported compliance with different personal preventive measures, as pointed out by Pan et al., (2020). The use of a multiple regression equation to predict COVID-19 preventive activities in a new epidemic was another key feature of this research. $\mathrm{P}$ (the COVID-19 prevention $)=4.344$ $0.115 \quad$ Female $\left(\mathrm{X}_{1}\right)+0.141 \quad$ Farmer $\left(\mathrm{X}_{2}\right)+0.356$ Trading $\left(\mathrm{X}_{3}\right)+0.733$ Traveled to an endemic $\operatorname{area}\left(\mathrm{X}_{4}\right)+0.253$ Age, 28-36 years $\left(\mathrm{X}_{5}\right)-0.546$ Age, $37-46$ years $\left(X_{6}\right)+0.317$ Age, $47-56$ years $\left(X_{7}\right)+0.151$ Age, $>56$ years $\left(\mathrm{X}_{8}\right)+0.318$ The perception of COVID-19 severity $\left(\mathrm{X}_{9}\right)-0.092$ The perceptions of COVID-19 risk $\left(\mathrm{X}_{10}\right)$. We hope to use the equations to design a self-defense program for COVID-19 or other communicable diseases that are major issues in many regions and contexts. One-third of the variation in preventive activity was predicted by the perception of disease severity toward COVID-19, according to the findings, as pointed out by Anaki and Sergay (2021). According, COVID-19 risk perception predicts compliance with COVID-19 preventive guidelines, according to the results of structural equation modeling (SEM), as pointed out by Plohl and Musil (2021). The findings of this study will be utilized to develop an intervention model for promoting, developing, and maintaining effective COVID-19 prevention practices, as well as maintaining and continuing them. Consistant, gender (female), age, the number of old individuals in one's family, perceived severity, perceived benefit, self-efficacy, poor family health, media exposure, knowledge, personal health status, and social support all had positive impacts on preventative behaviors, according to a regression analysis, as pointed out by Kim and Kim (2020).

\section{Conclusion}

This study showed the equation of multiple regression to predict COVID-19 prevention behaviors in a new epidemic. $\mathrm{P}$ (the COVID-19 prevention $)=4.344-0.115 \quad$ Female $\left(\mathrm{X}_{1}\right)+0.141$ Farmer $\left(\mathrm{X}_{2}\right)+0.356$ Trading $\left(\mathrm{X}_{3}\right)+0.733$ Traveled to an endemic area $\left(\mathrm{X}_{4}\right)+0.253$ Age, 28-36 years $\left(\mathrm{X}_{5}\right)$ 0.546Age, 37-46years $\left(\mathrm{X}_{6}\right)+0.317$ Age, 56years $\left(\mathrm{X}_{7}\right)+0.151 \mathrm{Age},>56$ years $\left(\mathrm{X}_{8}\right)+0.318$ The perception of COVID-19 severity $\left(\mathrm{X}_{9}\right)-0.092$ The perceptions of COVID-19 $\operatorname{risk}\left(\mathrm{X}_{10}\right)$. The results showed the people's perception of COVID-19 risk had no relationship to COVID-19 preventive behaviors. However, people's perception of COVID19 severity was shown to be significantly associated with COVID-19 prevention behaviors at 0.001 . Ultimately, the findings of this study will be utilized to develop an intervention model for promoting, implementing, and sustainable construction COVID-19 prevention practices. There should be cooperation from the private, public, and government sectors in implementing the model. However, GIS should be used for COVID-19 surveillance that is both effective and timely.

\section{Acknowledgment}

The researchers will be grateful to the president and administrators of Valaya Alongkorn Rajabhat University. The dean of the faculty of public health and all other partners in the project.

\section{Reference}

Anaki, D. and Sergay, J., 2021, Predicting Health Behavior in Response to the Coronavirus Disease (COVID-19): Worldwide Survey Results from Early March 2020. Plos one, Vol.16(1), 1-16, DOI:10.1371/ journal.pone. 0244534.

Cronbach, L. J., 1970, Essentials of Psychological Test (5th ed.). New York: Harper Collins.

Disease Control, Ministry of Public Health, 2021, Viralpneumonia, 1st Edition, (Thailand:Ministry of Public Health).

Dryhurst, S., Schneider, C. R., Kerr, J., Freeman, A. L., Recchia, G, Van Der Bles, A. M., Spiegelhalter, D. and Van Der Linden, S., 2020, Risk Perceptions of COVID-19 around the World. Journal of Risk Research. Vol. 23(7-8), 994-1006.

Duan, T., Jiang, H., Deng, X., Zhang, Q. and Wang, F., 2020, Government Intervention, Risk 
Perception, and the Adoption of Protective Action Recommendations: Evidence from the COVID-19 Prevention and Control Experience of China. International Journal of Environmental Research and Public Health, Vol.17(10), doi: 10.3390/ijerph17103387.

Kim, S. and Kim, S., 2020, Analysis of the Impact of Health Beliefs and Resource Factors on Preventive Behaviors against the COVID-19 Pandemic. International Journal of Environmental Research and Public Health, Vol.17(22), https://doi.org/10.3390/ijerph17228666.

Kwok, K. O., Li, K. K., Chan, H. H. H., Yi, Y. Y., Tang, A., Wei, W. I. and Wong, S. Y. S., 2020, Community Responses during Early Phase of COVID-19 Epidemic, Hong Kong. Emerging Infectious Diseases, Vol. 26(7), DOI:10.1101/2020.02.26.20028217.

Lee, M. and You, M., 2020, Psychological and Behavioral Responses in South Korea during the Early Stages of Coronavirus Disease 2019 (COVID-19). International Journal of Environmental Research and Public Health, Vol.17(9), 1-14, DOI:10.3390/ijerph17092977.

Mousavi, S. H., Delshad, M. H., Martellucci, C. A., Bhandari, D., Ozaki, A., Pourhaji, F. and Sah, R., 2021, Community Behavioral and Perceived Responses in the COVID-19 Outbreak in Afghanistan: A Cross-Sectional Study. Disaster Medicine and Public Health Preparedness, 1-7. DOI:10.1017/dmp.2021.135.

Ning, L., Niu, J., Bi, X., Yang, C., Liu, Z., Wu, Q., Ning, N., Liang, L., Liu, A., Hao, Y. and Gao, L., 2021, The Impacts of Knowledge, Risk Perception, Emotion and Information on Citizens' Protective Behaviors during the Outbreak of COVID-19: A Cross-Sectional Study in China. BMC Public Health. Vol. 20(1), 1-12. DOI:10.1186/s12889-020-09892-y.

Pan, Y., Fang, Y., Xin, M., Dong, W., Zhou, L., Hou, Q. and He, Y., 2020, Self-Reported Compliance with Personal Preventive Measures among Chinese Factory Workers at the beginning of Work Resumption Following the COVID-19 Outbreak:Cross-sectional Survey Study. Journal of Medical Internet Research, Vol. 22(9), 1-16. DOI:10.2196/22457.

Park, S. and Oh, S., 2021. Factors Associated with Preventive Behaviors for COVID-19 among Adolescents in South Korea. Journal of
Pediatric Nursing. DOI: 10.1016/j.pedn.2021.07.006.

Plohl, N. and Musil, B., 2021, Modeling Compliance with COVID-19 Prevention Guidelines: The critical Role of Trust in Science. Psychology, Health \& Medicine, Vol. 26(1), 112.

Quandt, S. A., LaMonto, N. J., Mora, D. C., Talton, J. W., Laurienti, P. J. and Arcury, T. A., 2020, COVID-19 Pandemic among Latinx Farmworker and Nonfarmworker Families in North Carolina: Knowledge, Risk Perceptions, and Preventive Behaviors. International Journal of Environmental Research and Public Health, Vol.17(16), 1-17, DOI:10.3390/ijerph17165786.

Sobkow, A., Zaleskiewicz, T., Petrova, D., GarciaRetamero, R. and Traczyk, J., 2020, Worry, Risk Perception, and Controllability Predict Intentions Toward COVID-19 Preventive Behaviors. Frontiers in Psychology, Vol. 11, 1-15, DOI:10.3389/fpsyg.2020.582720.

The Centre for the Administration of the Situation due to the Outbreak of the Communicable Disease Coronavirus 2019 (COVID-19), 2021, The Situation of the Communicable Disease Coronavirus 2019 (COVID-19) of July 12, 2021, Thailand: Ministry of Interior.

Unesco, 2020, Risk-Communication-SocialAwareness-Covid-19, UNESCO Office Jakarta.

Yamane, T., 1973, Statistics: An Introductory Analysis. 3rd Edition, Harper and Row, New York.

Yang, X. Y., Gong, R. N., Sassine, S., Morsa, M., Tchogna, A. S., Drouin, O., Chadi, N. and Jantchou, P., 2020, Risk Perception of COVID19 Infection and Adherence to Preventive Measures among Adolescents and Young Adults. Children, Vol. 7(12), DOI:10.2139/ssrn.3605214.

Yıldırım, M., Geçer, E. and Akgül, Ö., 2021, The Impacts of Vulnerability, Perceived Risk, and Fear on Preventive Behaviours against COVID19. Psychology, Health \& Medicine, Vol. 26(1), 35-43.

Zeballos Rivas, D. R., Lopez Jaldin, M. L., Nina Canaviri, B., Portugal Escalante, L. F., Alanes Fernández, A. M. and Aguilar Ticona, J. P., 2021, Social Media Exposure, Risk Perception, Preventive Behaviors and Attitudes during the COVID-19 Epidemic in La Paz, Bolivia: A Cross Sectional Study. PloS one, Vol.16(1), 112,DOI:10.1371/journal.pone.0245859. 